\title{
DENTAL FEAR AND PREMATURE TOOTH EXTRACTION
}

\author{
Radosveta Andreeva ${ }^{1}$, Hristina Arnautska ${ }^{2}$, Tihomir Georgiev ${ }^{3}$ \\ ${ }^{1}$ Department of Pediatric Dentistry, Faculty of Dental Medicine, \\ Medical University of Varna \\ ${ }^{2}$ Department of Orthodontics, Faculty of Dental Medicine, Medical University of Varna \\ ${ }^{3}$ Department of Oral and Maxillofacial Surgery, Faculty of Dental Medicine, \\ Medical University of Varna
}

\begin{abstract}
Dental avoidance is a high risk factor for development of odontophobia and poor oral health including premature tooth extraction in children.

The aim of this study is to evaluate the connection between dental fear and premature tooth loss. Subject of monitoring of the clinical research were 140 school children with mixed dentition. The clinical group consisted of 90 children with prematurely extracted teeth. The patients from the clinical group were divided into three groups of 30 patients. The control group consisted of 50 children with intact denture. A special questionnaire was filled in by the parents of the examined children regarding the dental fear of their children, whether there is such fear or not. The results show that while in the control group the majority of chil-

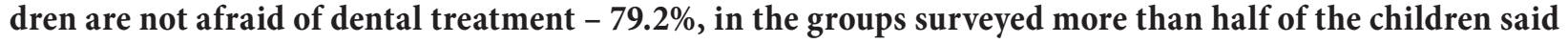
they were afraid of dental treatment, especially the ones from the third group $-57.7 \%$.

CONCLUSION: Children with prematurely extracted teeth have a higher level of dental anxiety due to which they suffer from poor dental health and early tooth loss. The use of behavioural techniques is recommended in order to improve their oral health.
\end{abstract}

Keywords: dental fear, premature extraction, primary teeth

\section{INTRODUCTION}

Dental fear, or dental anxiety, presents a problem for the treatment of patients suffering from it, and also for the dentist $(1,2)$. A high level of dental anxiety can influence the dental treatment in such way that it becomes almost impossible for the dentist

\footnotetext{
Address for correspondence:

Radosveta Andreeva

Faculty of Dental Medicine,

Medical University of Varna

55 Marin Drinov Str.

9002 Varna, Bulgaria

e-mail:doctor_ra@abv.bg
}

Received: May 9, 2016

Accepted: June 17, 2016 to complete the treatment (3). Many researches have shown that dental anxiety is one of the reasons for not seeking dental treatment $(1,4,5,6,7)$. Fear is often considered to be an essential emotion, a response in times of danger. It is therefore normal for younger patients to be afraid of new and potentially threatening situation like pulpitis and periodontitis treatment. It happens often that in such situations parents prefer to delay the treatment which leads to premature tooth extraction in children $(8,9,10)$.

The aim of this study is to evaluate the connection between dental fear and premature tooth loss.

\section{MATERIALS AND METHODS}

Subject of monitoring of the clinical research were 140 school children with mixed dentition. 
Radosveta Andreeva, Hristina Arnautska, Tihomir Georgiev

Table 1. Distribution of children from the surveyed groups according to the presence of fear of dental treatment

\begin{tabular}{|c|c|c|c|c|c|c|c|c|}
\hline \multirow{3}{*}{ Groups } & \multicolumn{6}{|c|}{ Is your child afraid of dental treatments? } & \multirow{2}{*}{\multicolumn{2}{|c|}{ Total }} \\
\hline & \multicolumn{2}{|c|}{ No } & \multicolumn{2}{|c|}{ Yes } & \multicolumn{2}{|c|}{ I cannot decide } & & \\
\hline & Number & $\%$ & Number & $\%$ & Number & $\%$ & Number & $\%$ \\
\hline Control group & 38 & 79.2 & 1 & 2.1 & 9 & 18.8 & 48 & 100 \\
\hline Group 1 & 9 & 45.0 & 7 & 35.0 & 4 & 20.0 & 20 & 100 \\
\hline Group 2 & 6 & 25.0 & 13 & 54.2 & 5 & 20.8 & 24 & 100 \\
\hline Group 3 & 7 & 26.9 & 15 & 57.7 & 4 & 15.4 & 26 & 100 \\
\hline $\begin{array}{l}\text { Statistical } \\
\text { significance }\end{array}$ & & & ${ }^{2}=37.56, d$ & & & & & \\
\hline
\end{tabular}

The clinical group consisted of 90 children with prematurely extracted teeth. The patients from the clinical group were divided into three groups of 30 patients. The control group consisted of 50 children with intact denture.

* Patients who have had one or more teeth extracted, who have come to the clinic during the first 2 months after the extraction and have no orthodontic problems.

* Patients with prematurely extracted temporary teeth 6 or more months earlier, with mild orthodontic problems.

* Patients with prematurely lost temporary teeth 6 or more months earlier who also have severe orthodontic problems (II and III class Angle).

The control group consisted of 50 children of the same age, who have had no premature extractions.

A special questionnaire was filled in by the parents of the examined children regarding the dental fear of their children, and whether there is such fear or not.

We used chi square test to test the hypothesis that there is no difference in the proportion of children experiencing fear between the groups. The level of statistical significance is set at alpha level 0.05.

\section{RESULTS}

A difference was found in the distribution of the groups according to the answer to the question „Is your child afraid of dental treatments?”. While in the control group the majority of children are not afraid of dental treatment $-79.2 \%$, in the clinical groups surveyed more than half of the children said they were afraid of dental treatment, especially the third group - 57.7\% $(\mathrm{P}<0.0001)($ Table 1$)$.

\section{DISCUSSION}

These results indicate that children who do timely visits to the dental office (control group), before the emergence of subjective symptoms, have less fear of dental treatment than patients from the studied groups. The dental treatment of children in the control group is most often prophylactic, noninvasive and painless. At the same time children from the examined groups associate their visit to the dentist with pain and therefore are afraid of dental treatment. Some of them have negative previous experience in the dental office. The use of behavioural techniques is recommended to influence the behaviour of children in order to reduce their fear of dental treatments (11).

\section{CONCLUSION}

The children with prematurely extracted teeth have a higher level of dental anxiety due to which they have poor dental health and early tooth loss. The use of behavioural techniques is recommended in order to improve their oral health.

\section{REFERENCES}

1. Smith TA, Heaton LJ. Fear of dental care: are we making any progress?. J Am Dent Assoc. 2003;134(8):1101-1108.

2. Folayan MO, Idehen EE, Ojo OO. The modulating effect of culture on the expression of dental anxiety in children: a literature review. Int J Paediatr Dent. 2004;14(4):241-245.

3. Armfield JM, Spencer AJ, Stewart JF. Dental fear in Australia: Who's afraid of the dentist?. Aust Dent J. 2006;51(1):78-85.

4. Schuller AA, Willumsen T, Holst D. Are there differences in oral health and oral health 
behavior between individuals with high and low dental fear?. Community Dent Oral Epidemiol. 2003;31(2):116-121.

5. Sohn W, Ismail AI. Regular dental visits and dental anxiety in an adult dentate population. J Am Dent Assoc. 2005;136(1):58-66.

6. Abrahamsson KH, Berggren U, Hallberg L, Carlsson SG. Dental phobic patients' view of dental anxiety and experiences in dental care: a qualitative study. Scand J Caring Sci. 2002;16(2):188-196.

7. Folayan MO, Idehen E. Factors influencing the use of behavioral management techniques during child management by dentists. J Clin Pediatr Dent. 2004;28(2):155-161.

8. Locker D. Psychosocial consequences of dental fear and anxiety. Community Dent Oral Epidemiol. 2003;31(2):144-151.

9. Moore R, Brodsgaard I, Rosenberg N. The contribution of embarrassment to phobic dental anxiety: a qualitative research study. BMC Psychiatry. 2004;4(1):10-14.

10. Frankel MR, Frankel LR. Some recent developments in sample survey design. J Market Res. 1977;14:280-293.

11. Neverlien PO. Assessment of a single-item dental anxiety question. Acta Odontol Scand. 1990;48(6):365-369. 